\title{
THE SOVEREIGNTY OF LEARNING, THE FORTUNES OF SCHOOLING AND THE NEW EDUCATIONAL VIRTUOUSNESS
}

\author{
by Pádraig Hogan, St Patrick's College Maynooth, National University of \\ Ireland
}

I. Sensibility as Property: The Designs of the New Virtuousness

It may seem a little otiose to raise in these pages the notion of the sovereignty of learning at a time when a decade of Conservative government in Britain has secured decisive measures to bring the conduct of schooling into conformity with its own championship of a market economy approach to social policy. The scope and the effects of this new ascendancy in Britain have been explored in a number of recent articles in this journal (Quicke, 1988; Turner, 1989; Jonathan, 1990). Educational reforms inspired by a similar kind of thinking, however, have been widely implemented in the United States during the decade of the 1980s. Some key features of the market approach have also infused educational discourse in other countries, notably Australia and Ireland.

It is precisely the international character of the new ascendancy of market thinking in education which gives fresh urgency to the all but eclipsed claims of the sovereignty of learning. Of particular significance in these international developments have been the following features: (a) the dramatic recasting of education itself as a product, or quantifiable commodity, rather than as an attempted encounter with one or other cultural tradition or discipline of learning; (b) the associated rise of a commercial vocabulary in educational discourse, for instance the characterisation of students and their parents as 'consumers' and of teachers as 'personnel' for the 'delivery' of the curriculum; and (c) the advocacy of vigorous competitiveness as the major instrument of educational advance, and the approbation of individual enterprise as one of its chief fruits. These three features mark a major mobilisation of moral energies on educational matters during the last decade, and constitute what may aptly be called a new educational virtuousness.

The international parallels sketched here may suggest that where 
ideals associated with the sovereignty of learning are concerned schooling has entered a new Dark Age. But before indulging any such suggestion, it may frankly be queried by the new virtuousness why learning as an enterprise should enjoy any sovereignty in the first place. Why should modern elected governments grant to publicly funded schooling powers and freedoms which the classical authors of Western civilization, such as Plato and Aristotle, were careful to reserve for the rulers of the state? The objection contained in the question gains further weight when we find hardly a handful of figures in the history of educational thought, including, this century, Karl Jaspers and Michael Oakeshott, who would uphold the autonomy, or sovereignty, of a human enterprise devoted to the pursuit of learning. Even Rousseau fails us in the final analysis in such a search, as does the anti-utilitarian champion of liberal learning, John Henry Newman. Recall, for instance, Rousseau's thoroughly conformist views on the education of girls (Sophie) and the remarkable extent of covert preparatory manipulation in his designs for the education of boys (Emile). Recall also Newman's acquiescence in Church authority over academic matters in the later Discourses of The Idea of a University. The history of educational institutions looks even bleaker than that of educational thought if we are seeking precedents for the sovereignty of learning. Could it be the case then that to grant the educational enterprise a dignified independence from current fashions and expedients in the world of getting and spending is a claim of dubious ancestry? Is this claim little more than a modern bid for power by an emergent liberal intelligentsia - a claim implicit in the writings of John Dewey, and imperfectly articulated thereafter by the pluralist educational philosophies of the 1960s and 70s? More specifically, is it an attempt by a growing establishment of professional educators to embrace a congenial but vaguely-defined tradition known as 'liberal education' - an establishment which hoped to dethrone older masters like church and state by capitalising on the rise of democratic sensibility in Western countries as the twentieth century advanced and grew more affluent?

If the suggestions contained in these questions unveil the truth of the matter; if the answer to each of the questions is substantially ' $y e s$ ', then the claim of sovereignty on behalf of learning can only be confirmed in its disarray. It is precisely this lingering disarray, this inadequacy of convincing philosophical articulation on the part of those professionally involved in the world of learning, which gives sustenance to a contrary claim from the new educational virtuousness. This contrary claim can be easily articulated, and in such a way that its own bid for democratic support is coherent and plausible. It is a 
claim which holds that educational thought and action must be regarded as essentially subservient to the political will of democratically elected governments; that the kinds of learning most valued by such governments must be promoted by schools, colleges and universities which enjoy receipts from the public purse; that educational practice must accordingly accept its standing as the handmaid of its resident upstairs masters, with no inherent entitlement to change how things are organised and conducted in its own downstairs chambers.

Much of the plausibility and the democratic aura of this claim fades, however, when it is placed under scrutiny; in particular, when we realise that it is a claim which harbours proprietorial designs on the sensibilities of pupils and presumes accordingly upon the commitments of teachers. For if the conduct of education is to be regarded as essentially subservient to the preferences and expedients of the current party in power, then such preferences and expedients can, without scruple, impose themselves on the commitments of teachers and on the daily efforts of pupils. It may be replied of course that a government's fears of being unseated in the next election should guarantee against any serious misuse of influence during its term of office. In the first place this reply ignores the possibility that a future alternative government may find it difficult to undo the more questionable work of its predecessor. Secondly, it assumes that the conduct of education can be validly compared to that of politics, where commitments are generally as strong as the currently stronger party. Thirdly, associated with this last assumption, it fails to acknowledge that there are enduring commitments which are binding on teaching as an occupation, just as there are on occupations like legal practice, nursing and medical practice, or religious ministry, commitments which may not be negotiable in the court of politics.

Without the provision of a coherent and robust account of such commitments, the new educational virtuousness may happily preside in the arena of learning much like a conquering prince in a vanquished province. Such provision is of course among the first tasks of the philosophy of education. But the philosophy of education cannot properly fulfil this task if, as in its dominant form of recent decades, it understands that it must (after Wittgenstein) 'leave everything as it is' and limit its legitimate scope to a 'second order' activity; or, more precisely, to a 'logical analysis of educational concepts' (see Peters \& Hirst, 1970). Notwithstanding the merits of strict logical analysis in deliberations on educational matters, the philosophy of education cannot be either fully coherent in itself, or robust in the face of political attacks on schooling, if it fails to 
acknowledge within its scope of enquiry the historical fortunes of educational concepts themselves. Concepts with dramatic, or sometimes vexed, careers in the history of schooling include those like discipline, authority, freedom, responsibility, obedience, punishment, accomplishment, dissent, indoctrination, compulsion, equity, aptitude, ability, intelligence, assessment, interests, discrimination, tradition, to mention but a selection from a much longer list. The historical fortunes of educational concepts, it must be pointed out, show them to be quite different from purely logical concepts, such as those of mathematics. They thus call for a kind of investigation which recognises their shifting emphases and nuances in the course of the history of education. These differing emphases and nuances have furthermore influenced the outlooks and the institutions which are inherited and modified by the educational discourse and practice of each historical present. It thus becomes clear that a claim to sovereignty by an enterprise with an enduring commitment to learning greatly weakens its own case if it entrusts the safeguarding of this case to a logical philosophy short of historical perspective. Such a claim is deeply imperilled, moreover, if its shortcomings in giving a coherent and convincing account of itself leave it an easy victim amid the well-lobbied counter claims which abound in the cursory arena of modern democratic politics.

The outcome seems inescapable, then, that if sovereignty of any significant kind is to be successfully sought for the claims of learning, a philosophical account of their entitlement to dignified treatment remains inadequate unless it includes a pertinent historical perspective on the ancestry and fortunes of such claims. From observations made a little earlier, it might be concluded that the history of educational thought, and that of educational institutions, may not prove too hospitable to such a project. This conclusion would indeed be true if the sovereignty being claimed for learning was absolute, or unconditional in character. The project might prove much more fruitful, however, if the sovereignty claimed for learning is to be understood in a conditional rather than an absolute sense; understood, that is, not as a separatist province of schooling, but rather as the sovereignty of an enterprise accountable to the public for the freedom accorded to it in its exercise of a distinct and difficult office. We should become clearer about the precise nature and scope of this office, together with the discretionary freedoms it may fairly expect, as the project itself unfolds in the following sections. 


\section{Three Ages of Learning: Antiquity, Ghristendom AND Modernity}

In one form or another, the notion of piety has from antiquity until the rise of pluralism in the modern period been a central one in the history of Western learning. Although piety is now often taken to be another name for puritanism, or moral oppressiveness, the classical origins of the concept associate it closely with an inner emancipation, a cultured reverence for ideals regarded as edifying and morally binding. Socrates, who left us no written testament of his own, but whom we know was convicted on a charge of impiety, was one of the best exemplars of what the most generous sense of this ancient virtue means. Not only is this clear from the everyday evidence of his lifelong commitment to learning to live worthily, but also from the dramatic events of the final days of his imprisonment. For instance, when provided with the chance of escape while awaiting his execution, his reverence for the sacredness of the Laws of Athens commanded him to decline the opportunity offered, and to explain his reasons patiently to his disappointed friends. Remaining with the classical period, the seminal writings of Plato and Aristotle on education, for all their notable differences, share an avowal of piety as a crucial characteristic: a devout concern for the good of the community, the Polis. In fact, if we fail to appreciate the authority and the subtlety of the concept of the Polis in Plato and in Aristotle, we risk caricaturing their arguments from the start, or understanding them in a naively superficial manner. The same is true of the writings of the two authors Cicero and Quintillian, which constitute the core of the Roman contribution to the educational traditions of the West. We might venture to translate Polis as 'the body politic', but this misses the point that what made the Polis a community was: (a) a shared understanding of being governed by some publicly recognised virtues (e.g. courage, truthfulness, pride); (b) a shared sense of disdain for some publicly recognised vices (e.g. cowardice, underhandedness, humility); (c) a shared avowal of the forceful, but ambivalent hand of the divinities in human affairs; and not least (d) the rather intimate scale of the Polis as a city state.

With the spread of Christianity, the notion of piety received a new emphasis and application. The coronation of Charlemagne as Holy Roman Emperor around 800 AD marked the institutional beginnings of a new cultural pattern which, despite recurring setbacks and even decisive rifts, was to remain the prevailing one in Western history for a thousand years. This cultural pattern, universally known as Christendom, had the most far reaching consequences for how the 
enterprise of education came to be understood and how its conduct came to be controlled. As William Boyd (1961) points out in his book, The History of Western Education, the pursuit of learning now came to be publicly viewed within boundaries fixed by the Church's interests and doctrines. This consecration of learning also meant that what the classical authors had viewed as the public community could no longer be seriously envisaged as a Polis, but rather as the universal kingdom of God-fearing Christians in obedience to their spiritual and temporal rulers.

In this brief outline we can see that the classical notion of piety, as an educational quality, became embraced and redefined by the notion of Christian virtuousness. But we also see that this event was accompanied by the consolidation of the power of the church in political and institutional forms. Thus the authority of a Christian metaphysics eventually became the universal rule for learning in Christendom. The tensions and ambiguities present in classical conceptions of piety accordingly gave way to the more exact precepts of Church teaching. The schisms which occurred during the history of the Church, including the Reformation and its extended aftermath, served to make such teaching even more exact, and often more exacting. In short, with the denominalization of Christendom, the importance of Ghurch authority and tradition increased rather than diminished. The consequences for the pursuit of learning and the control of schooling were both decisive and divisive in subsequent centuries.

The efforts of the Renaissance humanist Erasmus to shake the hold of medieval metaphysics on learning and to advance the study of the pagan classics as well as Christian literature are worthy of particular attention in any consideration of the education legacy of Christendom. It is important to note that the piety of learning was assumed, not abandoned, by Erasmus. The piety he embraced, however, also nurtured a penetrating critique of many of the institutionalised practices of Christendom itself, including schooling. It embodied, moreover, a liberating self-critical discipline which was quite foreign to the established routines of study and scholarship of his era. The liberties adroitly claimed and exercised by Erasmus in his writings are thus of seminal import for any case being made for the sovereignty of learning. His ideas found little immediate application, due to the sectarian religious turmoil which had already won the day in his later years, but they provided a powerful imaginative stimulus to the cause of learning. In fact, Erasmus' belief that learning is essentially an adventure rather than an ordeal, an enrichment rather than a conquest of sensibility, and that its benefits should be made available 
to all, not just the well-off, betoken commitments and aspirations which, had he stated them overtly, would have denied many of the underlying assumptions of educational practice in Christendom itself. To put it explicitly now, the practical thrust of Erasmus' humanism rests on the presupposition that, amid the continual struggle and tumble of enthroned and aspirant interests, there are enduring interests associated with learning which merit a civilised tolerance or sufferance from the authorities of church and realm; interests which are inherently educational in character, which are educational before they are ecclesiastical, or political, or commercial, or whatever. The point will be taken up a little later when considering the influence of the new educational virtuousness.

The long ascendancy of Christendom, and of ecclesiastically sanctioned virtues in education, was not effectively contested until the later eighteenth century by what is generally called the Enlightenment or the Age of Reason. The Enlightenment is identified as the age of challenge to the rule of established authority and tradition. It paved the way for revolutionary movements of many kinds and it gave birth to the critical spirit in ethics and politics known as the spirit of modernity (see MacIntyre, 1985; Gadamer, 1975). So, in summary, we can broadly identify three Ages which mark decisive shifts in how the purposes of the educational enterprise came to be envisaged. The first two of these, the Classical Age and the Age of Christendom, identified learning with successive versions - Pagan and Christian - of the virtue of piety. This long association was to be weakened progressively by the endemic turbulence of the Age of Modernity.

\section{The Many Fages of Modernity: From Radical Pluralism to Competitive Individualism}

To grasp the moral import of modernity it is necessary to emphasise the distinction between virtues and values. The word 'values' enjoys widespread currency nowadays. The word 'virtues' by contrast has connotations of the past and even a quaintly nostalgic ring. The distinction underlies the difference between sacred and secular conceptions of learning which occasioned intense acrimony in the wake of the Enlightenment. The Napoleonic sequel to the French Revolution for instance represented a decisive blow to the authority of religiously sanctioned virtues. The new system of state schools and universities signalled that the Bonapartist state had its own strategic interests in the arena of education and that these had little to do with the virtue of piety but rather with the training of loyal citizens and good soldiers, and the advancement of technical expertise. 
Where schooling was concerned, these interests now took precedence over any interests of the Church (Thompson, 1966, pp. 58-59). Not only in France, but throughout Europe, the nineteenth century increasingly became an era of rival conceptions of social and political order in which the rule of established authority and tradition, particularly that of royalty and the churches, was repeatedly subjected to attack. A proliferation of emergent ideologies, including industrialism, utilitarianism, nationalism, democracy, secularism, and communism, sought the allegiance of an increasingly urbanised and growing diverse public.

The critical spirit of modernity was embodied in different degrees in these various movements. Even so, contestability and disparateness were already taking root as definitive rather than occurrent characteristics of the moral and political climate of nations and societies. Associated with this was a new political conception of education as an instrument to be fought for, controlled and pressed into service in advancing the sphere of influence of aspirant ideologies.

We can see in these developments the origins of what we now call pluralism, that is, the co-existence in one society of groups and individuals whose basic outlooks are different in essential rather than in minor respects. The rise of Liberalism in politics was clearly linked to these developments. John Henry Newman's distaste for Liberalism in Britain, for instance, arose from his perception of its bland tolerance of different religious traditions, without accepting the binding authority of any of them. This example serves to highlight the difference between virtues and values. What virtues represented for upholders of a religious tradition, values came to represent for the critical spirit of modernity, particularly that spirit which disavows allegiance to a religious tradition. Strictly speaking, then, values are what the person who wishes to exercise a critical moral autonomy views herself or himself as freely choosing in any situation, without necessary avowal of religious authority or moral tradition. A commitment to virtues, by contrast, invariably involves a degree of deference to a tradition of belief and conduct, even if this deference is tacit, or unconscious, or qualified (e.g. religious traditions, patriotic traditions, trade union traditions, democratic traditions, hierarchic cultural traditions and so on).

It is widely held that the spirit of modernity, and its respect for freely chosen values, has finally come of age in those Western societies where a libertarian and secularist outlook has become the predominant one in the regulation of human affairs, including the arrangements for formal education. Such societies are regarded as having finally shaken off the burden of an oppressive metaphysics, as having appropriated 
technology to the efficient organisation of public affairs and as allowing their citizens freedom to pursue their individual interests, subject only to the constraints of civil law. Yet this modern triumph for individual liberties, notwithstanding its distinct advancement of human entitlements, has in itself much of a disquieting metaphysical character. That is to say, in its rationalist form of secular individualism, it harbours assumptions about the significance of being human and about the conduct of human affairs which may be as doctrinal and doctrinaire as any metaphysics furnished by classical, medieval or modern philosophy. Such doctrinal and doctrinaire features have been increasingly apparent during the last decade, most notably in the dramatic prominence of competitive individualism and 'market forces' in the social policies of many Western governments. These features are evident in a particular way in what was described at the outset as the new educational virtuousness. It is now necessary to examine the ancestry of this virtuousness at closer range.

\section{The Moral Angestry of the New Virtuousness}

The central virtue of the new educational virtuousness is not in itself a new virtue. It can neither be classed as one of the values of modernity, nor even as being educational in character. It is rather a virtue founded on the doctrine of classical economics that every member of society, by seeking his or her own material advantage, contributes best to the balanced functioning of society as a whole. Adam Smith laced this doctrine with theological flavour when he advocated it in The Wealth of Nations in 1776. Smith believed, in accordance with the teachings of his major philosophical work, The Theory of Moral Sentiments, that man's earthly self-interest would be tempered by God's providential benevolence, or more precisely by what he saw as the conscientious 'viceregents' of the Divine in each individual, and would thereby in the main be an enlightened self-interest. Thus Smith's doctrine, proclaimed in The Wealth of Nations, of the 'invisible hand' (of the Deity) averred that any hardships or indignities occasioned by the specialisation of labour would be compensated for by greater wealth for all, including labour. Notwithstanding Smith's detailed qualifications, unscrupulous readings of his theory soon gave an unprecedented respectability to economic greed which was rapidly embraced by landowners and industrialists who artfully overlooked any necessity to keep an ear tuned to the promptings of the 'viceregents' of Divine Providence. In short, doctrinaire self-interest soon became a respectable and powerful moral-political tradition in itself. 
What distinguished self-interest from straightforward greed in Smith's theory was the balance provided by the virtue of benevolence. Without this virtue, which for Smith was underwritten by his own belief in the indirect workings of Divine Providence, his theory could not count as a theory of the public good. Rather, it would now count only as a theory of wealth accumulation. As a discerning moral philosopher, Smith himself was scarcely unaware of this. His references to God as the 'Author of nature' and the 'Conductor of the universe' reveal, however, the curious innocence of his faith in Providence, and in what he called 'the natural progress of opulence'.

We are now so well acquainted with systematic exploitation of the vulnerable, with recurrences of genocide and with warfare on a global scale that the strategic role attributed to Providence by Smith can no longer be sustained in any convincing moral or political philosophy. Not so familiar, however, are two related conclusions which follow from this. Firstly, any respectability which acquisitiveness might nowadays seek to attribute to itself by locating its moral roots in Adam Smith's philosophy can be seen to be a spurious respectability. Secondly, the theory of 'public good through enlightened selfinterest', disrobed of its flawed religious underpinnings in Smith's arguments, can no longer plausibly count as a theory of the common good. Yet the recent renaissance of earthly individualism in many Western countries has been possible mainly because the governments in these countries have vigorously proclaimed as newly worthy virtues those springing from economic self-interest, or, in the new vocabulary, the virtues of 'privatization' in any field where a commitment to public funding has been traditionally involved.

Where the new virtuousness can legitimately claim some ancestry from Smith, however, is in its attitude to schooling as an instrument for the production of 'human capital'; in other words, the cultivation of learning with a view to harnessing its benefits to wealth creating 'employments which require extraordinary dexterity and skill' (The Wealth of Nations). Another feature of the new virtuousness which has clear origins in Smith's thinking is the currently controversial concept of 'merit pay' for teachers. Smith's advocacy in his Wealth of Nations of a forceful version of this concept argued that 'Publick services are never better performed than when their reward comes only in consequence of their being performed, and is proportioned to the diligence employed in performing them'. Smith seemed to regard teaching as an essentially laborious duty - an occupation with little promise of inherent reward for a freely given professional commitment. This rather parsimonious view is betrayed in his noted argument against standard salaries for teachers: 
It is in the interest of every man to live at much at his ease as he can; and if his emoluments are to be precisely the same, whether he does or does not perform some very laborious duty, it is certainly in his interest, at least as interest is vulgarly understood, either to neglect it altogether, or, if he is subject to some authority which will not suffer him to do this, to perform it in as careless and slovenly a manner as that authority will permit (The Wealth of Nations, Book V, ch 5).

The recasting of education as a sub-species of political economy, the portrayal of teaching as a necessary toilsome labour rather than as an occupational commitment to the advancement of learning, and the reluctance to acknowledge inherent dignity in learning itself are, then, the ancestral features of the new educational virtuousness. They mark a brusque disavowal of the more noteworthy traditions of learning which distinguished the classical and Christian periods of Western civilization. They also mark a decisive stage in the march of utilitarian ideas - from the incipient utilitarianism of Locke, through Smith's contributions, to the fully fledged utilitarianism of Bentham's Chrestomathia. Thus were nurtured the seeds of an industrious and commonsense oblivion, of a curt incomprehension towards any claim to sovereignty voiced by places of learning on behalf of pietas or humanitas.

\section{The New Virtuousness and the Interests of Education}

The rehabilitation of cupidity endorsed by the secularisation of classical economics proceeded in a new key during the 1980s. The remarkable renaissance of this economics became a major force not merely as a neo-classical fashion in political economy, but as an internationally emergent moral and political tradition. The educational virtuousness described in this essay as 'new' is so because it describes an unprecedented attempt by this emergent tradition to subject the conduct of learning to its own control. We need to make more explicit, then, the nature and scope of the claim which this virtuousness assumes over the interests of education. The first thing which must be pointed out in this connection is that the phrase 'the interests of education' is itself a likely candidate for the curt incomprehension mentioned just a moment ago. Clearly, the new virtuousness recognises key interests associated with schooling, but its first concern is to redefine these in terms of its own orthodoxies and to tailor them to the current priorities of government. In a speciously democratic way, the denial of sovereignty to the claims of learning is 
here as complete as anything decreed by the metaphysics of Christendom. Where the traditional concept of piety offered a subtle and inviting promise for advancing the claims and the culture of learning - a promise richly realised for instance by Erasmus - the brusqueness which attends the utilitarianism of the new virtuousness offers little such promise. Its awareness of the dignity of learning is obscured from the start by its doctrinaire preoccupation with the cost of learning and by the necessity to prepare human capital in the most useful and cost-effective way.

To speak of the interests of education, therefore, as a class of human interests entitled to civic dignity and protection is to call attention precisely to that which the new educational virtuousness has obscured. It is, firstly, to describe a culture of schooling which acknowledges its own indebtedness in a generous, yet critical way, to the richness which speaks in many voices from the achievements of earlier generations of learning which seek their continuation and enlargement in the earnest efforts of the present. It is to describe, moreover, the kind of teaching and learning which seeks always to be universally defensible, as distinct from sectional or partisan in its conduct; which engages both intellect and sensibility, but which entertains proprietorial designs on neither; which is assiduous in its efforts to unearth and to bring to fluency such abilities as are native to each pupil and are worthy of disciplined nurturing. In a word, the interests of education are more properly concerned with enablement than with inculcation, but not with just any kind of enablement. None of this is to suggest that technological studies or vocational training should be relegated in favour of the arts and pure sciences. Rather, it is to say that the elicitation and promotion of each pupil's ownmost promise where learning is concerned - whether that may ultimately lead the pupil towards an occupation as a poet or programmer, priest or politician - expresses the prior commitment of the interests of education.

The interests of education are properly pursued as a public concern through the conduct of formal schooling. Now this engagement is widely taken to be one of the major means for the cultivation and exercise of rationality by any society which avows a commitment to reason in the regulation of its public affairs. In this sense, the spirit of modernity itself, which subscribes in a particular way to the authority of reason, might provide an appropriate clue for understanding the scope and play of rationality in the interests of education and in the new educational virtuousness.

At once we encounter a possible pitfall. The everyday use of the words 'reason', 'rational', and 'rationality' to describe a central 
attribute of the form of practical life championed by modernity often obscures the fact that there is more than one rationality. This common oversight misses the point that rationality itself is always a characteristic of one or other culture, or way of life; that our conceptions of reason are invariably laden with a significant cultural past. There are, therefore, different rationalities, just as there are different cultures. Even within a single country the existence of different cultures and traditions signals the presence of different rationalities, sometimes conflicting rationalities. For example, rationality and practical reasoning will be envisaged very differently by the two following groups:

(a) those who understand social life primarily as an arena in which each individual or each group of individuals rightly seeks to maximise the satisfaction of his or her own wants and needs;

(b) those who understand social life primarily as an arena where the good of each individual is envisaged primarily as the counterpart of the promotion of the individual excellences of each and all.

From what has been argued so far it should be clear that the interests of education, or the claims of learning to enjoy some sovereignty, properly belong in the second group. Yet the new educational virtuousness seeks to place education in the first and to press the enterprise of learning itself into service in advancing the influence of an individualist culture. A moment's reflection is enough to alert us that enablement means quite different things in each context. One of the main consequences of the orthodox shift of educational endeavour to the individualist context in recent years is that schooling can thus concentrate on catering to those who are already seen to be agreeably industrious or compliant, and are thus judged to be on the road to reward and success by the rationality of the individualist culture. The corollary of this is that practical reasoning in such a culture can plausibly disclaim any but a minimal responsibility for those who fail to demonstrate the qualities of initiative in their studies; for those whose performance on so-called 'standard attainment' tests are an embarrassment to themselves; for those whose parents fail to show connoisseurship in their choice of school; in short, for those whom the new virtuousness more frankly regards as losers.

To return to the point mentioned in the opening sentence of this paper, where the new educational virtuousness has shown itself to be so successful in imposing its writ, it may seem foolhardy to argue any case for the sovereignty of learning. Such a doleful conclusion, however, betrays both the mentality of the vanquished and an 
ignorance of history. More specifically, it overlooks two crucial points. Firstly, had the conduct of learning, from the infant school to the university, been circumspect in its own pursuit of the interests of education during the expansionary decades of the 1960s and 1970s; had the fashions which then became prominent in the social sciences and educational studies nurtured the discipline of self-criticism as much as they nurtured that of critique; the case of learning would have been much more ably served and the new educational virtuousness would have had much more difficult pickings. The benefits of hindsight have a salutary lesson to teach here. Secondly, the most inhospitable of circumstances for the interests of education can force a new concentration of minds on essentials in the conduct of teaching and learning, and thus gradually give energy and momentum to a quality of educational leadership previously absent among teachers, school principals, academics and educational managements. Such circumstances can provoke the emergence of a new and circumspect tradition of educational leadership. An emergent tradition of this kind, where it is newly aware of the defensibility and the vulnerability of the interests of education, is also conscious of the necessity not to court the favour of politicians, but to earn the enduring respect of pupils and of parents for the achievements of schools and colleges. By acknowledging in a radically new way that teachers, pupils and parents share a common purpose, local school managements can pursue new opportunities to support and defend the earnest efforts of schools and colleges, and to uphold their achievements before the public. By such honest means, rather than by the devices of propaganda, are the interests of education served in a democracy. By such means also are the public's elected representatives properly apprised of the dignity and the merited sovereignty of learning.

\section{REFERENCES}

BOYD, W. (1961) The History of Western Education (Revised edition by E. J. KING) (London, Adam \& Charles Black).

GADAMER, H. G. (1975) Truth and Method (Translated by G. Barden \& Cumming) (London, Sheed \& Ward).

JONATHAN, R. (1960) State education service or prisoner's dilemma: the hidden hand as source of education policy British Journal of Educational Studies, 38(2), 116132.

MAGINTYRE, A. (1985) After Virtue: A Study in Moral Theory (2nd ed) (London, Duckworth).

PETERS, R. S. and HIRST, P. H. (1970) The Logic of Education (London, Routledge \& Kegan Paul). 


\section{THE SOVEREIGNTY OF LEARNING}

QUICKE, J. (1988) The New Right and Education British Journal of Educational Studies, 36(1), 5-20.

THOMPSON, D. (1966) Europe Since Napoleon (Harmondsworth, Penguin Books). TURNER, J. (1989) The open market in higher education: the universities \& the future British Journal of Educational Studies, 37(2), 99-110.

Correspondence:

Dr P. Hogan

Education Department

St. Patrick's College

Maynooth

Co. Kildare

Ireland 